\title{
Analisis Perbedaan Persepsi Mahasiswa Jurusan Akuntansi Terhadap Profesi Akuntan Publik (Studi Kasus Pada Mahasiswa Jurusan Akuntansi Politeknik Pos Indonesia Sebelum dan Sesudah Menempuh Mata Kuliah Auditing)
}

\author{
Riani Tanjung ${ }^{1}$, Khairaningrum Mulyanti ${ }^{2}$, Y. Casmadi ${ }^{3}$ \\ ${ }^{1}$ Prodi D3 Akuntansi, Politeknik Pos Indonesia \\ Email: rianitanjung@poltekpos.ac.id \\ ${ }^{2}$ Prodi D4 Akuntansi Keuangan Politeknik Pos Indonesia \\ Email: khairingrum@poltekpos.ac.id \\ ${ }^{3}$ Prodi D3 Akuntansi Politeknik Pos Indonesia \\ Email: casmadi@poltekpos.ac.id
}

\begin{abstract}
The interest of accounting students at the Indonesian Postal Polytechnic regarding the public accounting profession is still very lacking, this is seen from the number of accounting students who participate in a small number of street vendors or internships in KAP and KKP. The purpose of this study was to determine the differences in perceptions of accounting students at the Polytechnic Post Indondesia before and after taking auditing courses on the public accounting profession. The method of determining the sample used in this study is a simple random sampling method with sampling techniques using the Slovin formula. The analysis used was the validity test, reliability test and Mann Whitney test. The results showed that the perceptions of Indonesian Postal Polytechnic accounting students who had not taken auditing courses on public accountants amounted to $94 \%$ and for those who had covered $92 \%$ agreed, then it could be concluded that there was no significant difference between the perceptions of students in Accounting Polytechnic Pos Indonesia before and after taking auditing courses on the public accounting profession.
\end{abstract}

Keywords: Before \& After Taking Auditing Courses, Public Accountants

\begin{abstract}
ABSTRAK
Minat mahasiswa jurusan akuntansi di Politeknik Pos Indonesia mengenai profesi akuntan publik masih sangat kurang, hal ini dilihat dari jumlah mahasiswa akuntansi yang sebagian kecil mengikuti PKL atau internship di KAP maupun KKP. Tujuan penelitian ini untuk mengetahui perbedaan persepsi mahasiswa jurusan akuntansi Politeknik Pos Indondesia sebelum dan sesudah menempuh mata kuliah auditing terhadap profesi akuntan publik. Metode penentuan sampel yang digunakan dalam penelitian ini adalah metode simple random sampling dengan teknik pengambilan sampel menggunakan rumus slovin. Analisis yang digunakan adalah uji validitas, uji realibiltas dan uji mann whitney. Hasil penelitian menunjukkan bahwa persepsi mahasiswa jurusan akuntansi Politeknik Pos Indonesia yang belum menempuh mata kuliah auditing terhadap akuntan publik sebesar 94\% dan untuk yang sudah menempuh sebesar $92 \%$ menjawab setuju, maka dapat diambil kesimpulan bahwa tidak terdapat perbedaan yang signifikan antara persepsi mahasiswa jurusan akuntansi Politeknik Pos Indonesia sebelum dan sesudah menempuh mata kuliah auditing terhadap profesi akuntan publik.
\end{abstract}

Kata Kunci : Sebelum \& Sesudah Menempuh Mata Kuliah Auditing, Akuntan Publik

\section{PENDAHULUAN}

Latar Belakang

http://ejurnal.poltekpos.ac.id/index.php/competitive | 14 
Akuntan memiliki peran besar untuk meningkatkan transparansi dan kualitas informasi keuangan demi terwujudnya perekonomian nasional yang sehat dan efisien. Tidak ada proses akumulasi dan distribusi sumberdaya ekonomi yang tidak memerlukan campur tangan profesi Akuntan. Akuntan berperan disemua sektor yaitu publik, privat, dan nirlaba. Profesi Akuntan menyebar di dalam dan di luar instansi pemerintah. Disektor publik, Akuntan dapat mendorong pengelolaan keuangan negara agar berjalan semakin tertib, jelas, transparan, dan semakin akuntabel. Di sektor swasta, Akuntan menyiapkan laporan keuangan yang terpercaya dan dapat diandalkan.

Keberadaan para akuntan merupakan ruang besar bagi profesi ini untuk memberi warna bagi kehidupan berbangsa dan bernegara dalam menjaga kepentingan publik. Pemerintah pusat dan daerah, kementerian lembaga, perseroan terbatas, BUMN, BUMD, UKM dan koperasi, yayasan, ormas, serta partai politik, membutuhkan jasa akuntan dalam pengelolaan dan pertanggungjawaban sumber daya mereka. Eksistensi akuntan penting dan strategis untuk membangun culture birokrasi dan bisnis yang kuat, visioner, memegang teguh nilai-nilai etika, dan fokus terhadap nilai tambah bagi perekonomian nasional. (www.iaiglobal.or.id)

Menurut Sodikin (2014: 7) akuntan publik adalah akuntan yang bergerak dalam bidang akuntansi publik, yaitu menyerahkan rupa-rupa jasa akuntansi untuk organisasi bisnis ataupun non bisnis. Atas penyerahan jasa-jasa itu, akuntan publik memperoleh kontra prestasi yang biasa disebut fee.

Menurut buku SPAP (2011:1) tanggung jawab profesi akuntan publik tidak hanya terbatas pada kepentingan klien atau pemberi kerja. Ketika bertindak untuk kepentingan publik, setiap praktisi harus mematuhi dan menerapkan seluruh prinsip dasar dan kode etik profesi yang diatur dalam kode etik ini.

Dengan diterbitkannya Undang-Undang Nomor 5 Tahun 2011 maka semua akuntan publik yang berada di wilayah Republik Indonesia harus mentaati segala aturan dan ketentuan yang tercantum di dalamnya.Namun terbitnya Undang-Undang Nomor 5 Tahun 2011 menimbulkan pro dan kontra terutama dikalangan profesi akuntan publik dan mahasiswa jurusan akuntansi.

Beberapa pasal yang terkandung didalamnya dinilai merugikan para akuntan publik dan mahasiswa jurusan akuntansi. Seperti halnya yang tercantum dalam Pasal 6 huruf a mengenai perizinan untuk menjadi akuntan publik disebutkan seseorang dapat menjadi seorang akuntan publik salah satunya dengan syarat apabila memiliki sertifikat tanda lulus ujian profesi akuntan publik yang sah. Persyaratan ini dalam penjelasan Undang-Undang Nomor 5 Tahun 2011 dikatakan yang dapat mengikuti pendidikan profesi akuntan publik adalah seseorang yang memiliki pendidikan minimal strata 1 (S-1), diploma IV (D-IV), atau yang setara. Pernyataan ini mengandung makna bahwa semua disiplin ilmu diluar akuntansi dapat menjadi seorang akuntan apabila memiliki sertifikat tanda lulus ujian profesi akuntan publik.

Gambaran diatas menunjukkan bahwa mahasiswa akuntansi dihadapkan dalam beberapa pilihan untuk menjadi seorang akuntan. Dengan berbagai macam persyaratan dan mekanisme yang harus dilalui untuk menjadi seorang akuntan, sedikit banyak mempengaruhi persepsi seorang mahasiswa untuk menjadi seorang akuntan. Di Indonesia sendiri, perbandingan ketersediaan akuntan publik dengan kebutuhan dunia kerja, tidak seimbang dengan jumlah penduduk yang ada. Oleh sebab itu, menjadi seorang akuntan publik seharusnya menjadi pilihan karier yang utama bagi mahasiswa jurusan akuntansi karena masih sangat dibutuhkannya akuntan-akuntan publik untuk bekerja di Indonesia.

Pilihan karier merupakan suatu proses dari individu sebagai usaha mempersiapkan dirinya untuk memasuki tahapan yang berhubungan dengan pekerjaan. Selain itu persepsi mahasiswa umumnya dipengaruhi oleh pengetahuan pribadi mengenai lingkungan kerja, informasi dari lulusan terdahulu, keluarga, dosen, dan berbagai buku serta artikel yang dibaca ataupun digunakan. Berbagai informasi yang diperoleh mahasiswa akuntansi mengenai profesi akuntan publik merupakan hal yang penting dalam proses pengambilan keputusan kariernya sebagai seorang akuntan publik.

Adapun minat mahasiswa jurusan akuntansi di Politeknik Pos Indonesia mengenai Akuntan Publik masih sangat kurang, ini dibuktikan dengan jumlah mahasiswa akuntansi yang terdiri dari 530 orang hanya sebagian kecil yang mengikuti Praktek Kerja Lapangan atau http://ejurnal.poltekpos.ac.id/index.php/competitive | 15 
internship di Kantor Akuntan Publik maupun Kantor Konsultan Pajak. Berdasarkan data yang penulis dapatkan mengenai jumlah mahasiswa yang melakukan magang di KAP maupun KKP adalah sebagai berikut :

Tabel 1.1 Mahasiswa Jurusan Akuntansi yang Melakukan PKL \& Internship

\begin{tabular}{|l|c|c|l|}
\hline Tahun & Prodi D3 & Prodi D4 & \multicolumn{1}{c|}{ Keterangan } \\
\hline 2012 & 3 Orang & - & $\begin{array}{l}\text { KAP Achmad, Rasyid, Hisbullah \& Jerry dan KAP } \\
\text { Roebiandini \& Rekan }\end{array}$ \\
\hline 2013 & 2 Orang & - & KAP Roebiandini \& Rekan \\
\hline 2014 & - & - & Tidak Ada \\
\hline 2015 & - & 2 Orang & KAP Roebiandini \& Rekan \\
\hline 2016 & - & 3 Orang & KAP Roebiandini \& Rekan \\
\hline 2017 & - & 5 Orang & KAP Roebiandini \& Rekan \\
\hline
\end{tabular}

Sumber : Staff Administrasi D3 dan D4 Akuntansi Politeknik Pos Indonesia

Dari data diatas dapat dilihat peningkatan dan penurunan yang belum begitu signifikan. Hal itu bisa saja terjadi karena beberapa faktor yang membuat mahasiswa jurusan akuntansi belum begitu tertarik untuk melakukan magang di KAP maupun KKP.

Melihat dari kenyataan diatas, penulis tertarik untuk meneliti bagaimana persepsi mahasiswa akuntansi terhadap profesi akuntan publik sebelum dan sesudah menempuh mata kuliah auditing terkhusus yang berada di lingkungan kampus Politeknik Pos Indonesia. Maka dari itu penulis tertarik melakukan penilitian dengan judul " Analisis Persepsi Mahasiswa Jurusan Mahasiswa Akuntansi Politeknik Pos Indonesia Sebelum dan Sesudah Menempuh Mata Kuliah Auditing terhadap Profesi Akuntan Publik".

\section{Tujuan Penelitian}

Tujuan dilakukan penelitian ini Tujuan dalam penelitian ini untuk mengetahui perbedaan persepsi mahasiswa jurusan akuntansi Politeknik Pos Indondesia sebelum dan sesudah menempuh mata kuliah auditing terhadap profesi akuntan publik.

\section{METODE PENELITIAN}

\section{Jenis Penelitian}

Dalam penelitian ini metode penelitian yang digunakan yaitu metode kuantitatif. Penelitian ini juga menggunakan metode penelitian survey. Menurut Sugiyono (2014:6) "Penelitian survey digunakan untuk mendapatkan data dari tempat tertentu yang alamiah (bukan buatan), tetapi peneliti melakukan perlakuan dalam pengumpulan data ".

\section{Sumber Data}

Dalam penelitian ini, sumber data yang penulis gunakan adalah data primer. Merurut Sugiyono (2014:137) "sumber primer adalah sumber data yang langsung memberikan data kepada pengumpul data, misalnya melalui kuesioner, wawancara, dan observasi.".Data primer yang diperoleh pada penelitian ini yaitu kuisioner.

\section{Metode Pengumpulan Data}

Dalam metode ini, penulis menggunakan beberapa metode sebagai berikut:

1. Wawancara (Interview)

Wawancara digunakan sebagai teknik pengumpulan data, apabila peneliti ingin melakukan studi pendahuluan untuk menemukan permasalahan yang harus diteliti dan juga apabila peneliti 
ingin mengetahui hal-hal dari responden yang lebih mendalam. Wawancara ini ditujukan ke bagian staff jurusan akuntansi Politeknik Pos Indonesia.

\section{2. $\quad$ Angket (kuesioner)}

Metode kuesioner ini sering disebut dengan wawancara tertulis, dengan beberapa perbedaan. Melalui metode ini penulis membuat pertanyaan secara tertulis seputar masalah yang terkait dengan penelitian kemudian pertanyaan- pertanyaan tertulis tersebut diberikan kepada sampel untuk dijawab oleh mereka secara tertulis sesuai dengan petunjuk-petunjuk yang telah diberikan oleh penulis. Adapun angket ini ditujukan kepada mahasiswa jurusan akuntansi Politeknik Pos Indonesia.

3. Pengamatan (Observation)

Menurut Sutrisno Hadi yang dikutip oleh Sugiyono (2015:145) mengemukakan bahwa, Observasi merupakan suatu proses yang komplek, suatu proses yang tersusun dari berbagai proses biologis dan psikologis. Dua diantaranya yang terpenting adalah proses-proses pengamatan dan ingatan. 4. Studi Kepustakaan (Literature Research)

Studi kepustakaan atau studi literatur merupakan salah satu teknik pengumpulan data yang diperoleh dari berbagai literatur (seperti buku, jurnal akuntansi, internet dan lain-lain) yang menunjang pelaksanaan penelitian,yang bertujuan untuk memperoleh informasi dan pengetahuan serta teori - teori yang relevan dengan masalah yang akan dibahas seperti buku-buku auditing dan jurnal yang berhubungan dengan penelitian.

\section{Teknik Analisis}

Teknik analisis yang digunakan dalam penelitian ini adalah teknik analisis kuantitatif. Peneliti membandingkan persepsi mahasiswa jurusan akuntansi Politeknik Pos Indonesia sebelum dan sesudah menempuh mata kuliah auditing terhadap profesi akuntan publik. Dalam menganalisis masalah dan data yang diperoleh untuk dapat membuktikan hipotesis yang ada, peneliti menggunakan piranti lunak SPSS versi 20 sebagai alat bantu. Adapun teknik analisis data yang digunakan peneliti berdasarkan tujuan penelitian ini yaitu: uji validitas, uji realibilitas dan uji mann whitney.

\section{HASIL DAN PEMBAHASAN}

\section{Hasil Penelitian}

\section{Validitas \& Realibilitas}

Dalam penelitian ini, pengujian validitas dan ralibilitas diambil dari data hasil penyebaran kuesioner yang terdiri dari 35 item pertanyaan yang dijabarkan masing-masing 18 butir pertanyaan untuk variabel persepsi mahasiswa, dan 17 butir pertanyaan untuk variabel profesi akuntan publik. Dalam penelitian ini uji validitas dilakukan untuk seluruh variabel karena setiap butir pertanyaan perlu untuk diuji validitasnya.

Setelah dihitung menggunakan bantuan Software SPSS for windows version 20.00, berikut ini gambar hasil validitas kuesioner variabel pengalaman :

\begin{tabular}{|c|c|c|c|}
\hline Pernyataan & $\boldsymbol{R}_{\text {hitung }}$ & $\boldsymbol{R}_{\text {kritis }}$ & Keputusan \\
\hline 1 & 0,461 & 0,3 & Valid \\
\hline 2 & 0,441 & 0,3 & Valid \\
\hline 3 & 0,497 & 0,3 & Valid \\
\hline 4 & 0,597 & 0,3 & Valid \\
\hline
\end{tabular}




\begin{tabular}{|c|c|c|c|}
\hline 5 & 0,681 & 0,3 & Valid \\
\hline 6 & 0,461 & 0,3 & Valid \\
\hline 7 & 0,458 & 0,3 & Valid \\
\hline 8 & 0,665 & 0,3 & Valid \\
\hline 9 & 0,653 & 0,3 & Valid \\
\hline 10 & 0,628 & 0,3 & Valid \\
\hline 11 & 0,441 & 0,3 & Valid \\
\hline 12 & 0,505 & 0,3 & Valid \\
\hline 13 & 0,584 & 0,3 & Valid \\
\hline 14 & 0,573 & 0,3 & Valid \\
\hline 15 & 0,637 & 0,3 & Valid \\
\hline 16 & 0,665 & 0,3 & Valid \\
\hline 17 & 0,681 & 0,3 & Valid \\
\hline 18 & 0,637 & 0,3 & Valid \\
\hline
\end{tabular}

Tabel 3.1 Hasil Uji Validitas Variabel $\mathrm{X} 1$

Sumber data primer: (Kuesioner Diolah dengan Program SPSS)

Tabel 3.2 Hasil Uji Validitas Variabel X2

\begin{tabular}{|c|c|c|c|}
\hline Pernyataan & $\boldsymbol{R}_{\text {hĩtung }}$ & $\boldsymbol{R}_{\text {keritīs }}$ & Keputusan \\
\hline 1 & 0,361 & 0,3 & Valid \\
\hline 2 & 0,441 & 0,3 & Valid \\
\hline 3 & 0,552 & 0,3 & Valid \\
\hline 4 & 0,59 & 0,3 & Valid \\
\hline
\end{tabular}




\begin{tabular}{|c|c|c|c|}
\hline 5 & 0,575 & 0,3 & Valid \\
\hline 6 & 0,449 & 0,3 & Valid \\
\hline 7 & 0,552 & 0,3 & Valid \\
\hline 8 & 0,593 & 0,3 & Valid \\
\hline 9 & 0,575 & 0,3 & Valid \\
\hline 10 & 0,531 & 0,3 & Valid \\
\hline 11 & 0,491 & 0,3 & Valid \\
\hline 12 & 0,587 & 0,3 & Valid \\
\hline 13 & 0,597 & 0,3 & Valid \\
\hline 14 & 0,622 & 0,3 & Valid \\
\hline 15 & 0,59 & 0,3 & Valid \\
\hline 16 & 0,348 & 0,3 & Valid \\
\hline 17 & 0,575 & 0,3 & Valid \\
\hline 18 & 0,468 & 0,3 & Valid \\
\hline
\end{tabular}

Sumber data primer: (Kuesioner Diolah dengan Program SPSS)

Tabel 3.3. Hasil Uji Validitas Variabel Y

\begin{tabular}{|c|c|c|c|}
\hline Pernyataan & $\boldsymbol{R}_{\text {hitung }}$ & $\boldsymbol{R}_{\text {kritis }}$ & Keputusan \\
\hline 1 & 0,489 & 0,3 & Valid \\
\hline 2 & 0,592 & 0,3 & Valid \\
\hline 3 & 0,553 & 0,3 & Valid \\
\hline 4 & 0,353 & 0,3 & Valid \\
\hline 5 & 0,526 & 0,3 & Valid \\
\hline 6 & 0,484 & 0,3 & Valid \\
\hline 7 & 0,642 & 0,3 & Valid \\
\hline 8 & 0,573 & 0,3 & Valid \\
\hline 9 & 0,572 & 0,3 & Valid \\
\hline 10 & 0,53 & 0,3 & Valid \\
\hline 11 & 0,592 & 0,3 & Valid \\
\hline 12 & 0,532 & 0,3 & Valid \\
\hline 13 & 0,407 & 0,3 & Valid \\
\hline
\end{tabular}




\begin{tabular}{|c|c|c|c|}
\hline 14 & 0,384 & 0,3 & Valid \\
\hline 15 & 0,556 & 0,3 & Valid \\
\hline 16 & 0,491 & 0,3 & Valid \\
\hline 17 & 0,541 & 0,3 & Valid \\
\hline
\end{tabular}

Sumber data primer: (Kuesioner Diolah dengan Program SPSS)

Tabel 3.4. Hasil Uji Reliabilitas X1, X2 Terhadap Y

\begin{tabular}{|c|c|c|c|}
\hline Variabel yang diukur & Cronbach's Alpha & $\begin{array}{c}\text { Standarized } \\
\text { Alpha }\end{array}$ & Keterangan \\
\hline $\mathrm{X} 1$ & 0,909 & 0,6 & Reliabel \\
\hline $\mathrm{X} 2$ & 0,888 & 0,6 & Reliabel \\
\hline $\mathrm{Y}$ & 0,876 & 0,6 & Reliabel \\
\hline
\end{tabular}

Sumber data primer: (Kuesioner Diolah dengan Program SPSS)

Berdasarkan tabel uji validitas dan reliabilitas diatas dapat disimpulkan bahwa kuesioner yang digunakan dalam penelitian dapat dikatakan layak dalam mengukur apa yang ingin diukur dan dapat menghasilkan data yang sama pada penelitian dengan objek yang sama.

\section{Uji Mann Whitney}

Uji Mann Whitney menjadi alternatif ketika data tidak normal dalam uji independent sampel t test (parametrik). Seperti halnya dalam uji independent sampel t test, uji mann whitney dilakukan untuk mengetahui perbedaan dua sampel yang tidak berhubungan atau berpasangan satu sama lainnya. Untuk dasar pengambilan keputusan adalah sebagai berikut :

1. Jika nilai Asymp.Sig (2-tailed) $<0,05$, maka terdapat perbedaan yang signifikan

2. Jika nilai Asymp.Sig (2-tailed) $>0,05$, maka tidak terdapat perbedaan yang signifikan.

Dalam melakukan pengujian man whitney, pengolahan data penelitian menggunakan program statistik Software SPSS for windows version 20.00. Hasil pengujian nilai mann whitney antara persepsi mahasiswa sebelum dan sesudah menempuh mata kuliah auditing terhadap akuntan publik, dapat dilihat pada tabel dibawah ini :

Tabel 3.5 Uji Mann Whitney Test Statistics

\begin{tabular}{|l|l|}
\hline & Responden \\
\hline Mann-Whitney U & 1851,500 \\
Wilcoxon W & 3996,500 \\
$Z$ & \\
$\begin{array}{l}\text { Asymp. Sig. (2- } \\
\text { tailed) }\end{array}$ &, 224 \\
\hline
\end{tabular}

Sumber data primer: (Kuesioner Diolah dengan Program SPSS)

Berdasarkan perhitungan program SPSS for windows version 20.00 (Statistic Program for Social Science, maka didapat nilai Asymp. Sig. (2-tailed) yaitu 0,224 >0,05, maka dapat diambil kesimpulan 
bahwa tidak terdapat perbedaan yang signifikan antara persepsi mahasiswa jurusan akuntansi Politeknik Pos Indonesia sebelum dan sesudah menempuh mata kuliah auditing terhadap profesi akuntan publik.

\section{Pembahasan}

\section{Tanggapan Responden Variabel X1 terhadap Variabel Y}

Pada penelitian ini persepsi mahasiswa diukur menggunakan 9 indikator dan dioperasionalisasikan menjadi 35 pernyataan. Berikut ini adalah pembahasan mengenai indikatorindikator tanggapan responden mengenai persepsi mahasiswa Politeknik Pos Indonesia sebelum menempuh mata kuliah auditing terhadap profesi akuntan publik. Diantaranya sebagai berikut:

1. Indikator 1 (motivasi kualitas) terdiri dari 5 pernyataan.

2. Indikator 2 (motivasi karir) terdiri dari 5 pernyataan.

3. Indikator 3 (minat mengikuti PPAk) terdiri dari 5 pernyataan.

4. Indikator 4 (pengetahuan tentang akuntan publik) terdiri dari 3 pernyataan.

5. Indikator 5 (hak akuntan publik) terdiri dari 3 pernyataan

6. Indikator 6 (kewajiban akuntan publik) terdiri dari 3 pernyataan

7. Indikator 7 (tanggung jawab profesi) terdiri 3 pernyataan

8. Indikator 8 (perilaku profesional) terdiri dari 3 pernyataan

9. Indikator 9 (pilihan karir sebagai akuntan publik) terdiri dari 5 pernyataan

Tabel 3.6 Tanggapan Responden Variabel X1 tehadap Variabel Y

\begin{tabular}{|l|r|r|r|r|r|}
\hline \multirow{2}{*}{ Indikator } & \multicolumn{5}{|c|}{ Tanggapan Responden } \\
\cline { 2 - 6 } & \multicolumn{1}{|c|}{ SS } & \multicolumn{1}{c|}{ S } & \multicolumn{1}{c|}{ R } & \multicolumn{1}{c|}{ TS } & STS \\
\hline Motivasi Kualitas & $53 \%$ & $45 \%$ & $2 \%$ & $0 \%$ & $0 \%$ \\
\hline Motivasi Karir & $46,8 \%$ & $51 \%$ & $2 \%$ & $0,2 \%$ & $0 \%$ \\
\hline Minat mengikuti PPAk & $33,8 \%$ & $56,4 \%$ & $9,4 \%$ & $0,4 \%$ & $0 \%$ \\
\hline Pengetahuan tentang AP & $30,0 \%$ & $53,0 \%$ & $16,0 \%$ & $1 \%$ & $0 \%$ \\
\hline Hak Akuntan Publik & $39,0 \%$ & $57,0 \%$ & $4,0 \%$ & $0 \%$ & $0 \%$ \\
\hline Kewajiban Akuntan Publik & $43 \%$ & $51 \%$ & $5 \%$ & $1 \%$ & $0 \%$ \\
\hline Tanggung Jawab Profesi AP & $62,4 \%$ & $36,3 \%$ & $1 \%$ & $0,3 \%$ & $0 \%$ \\
\hline Perilaku Profesional & $39,3 \%$ & $48,8 \%$ & $10,6 \%$ & $1 \%$ & $0 \%$ \\
\hline Pilihan Karir sebagai AP & $38 \%$ & $53,4 \%$ & $8 \%$ & $0,6 \%$ & $0 \%$ \\
\hline Akumulasi Jawaban Responden & $\mathbf{4 4}$ & $\mathbf{5 0}$ & $\mathbf{6}$ & $\mathbf{0}$ & $\mathbf{0}$ \\
\hline
\end{tabular}

(Sumber : Data primer diolah)

Dari tabel diatas dapat dilihat bahwa sebesar $44 \%$ responden menjawab sangat setuju, $50 \%$ responden menjawab setuju, $6 \%$ responden menjawab ragu-ragu, $0 \%$ responden menjawab tidak setuju dan sangat tidak setuju. Jika diakumulasikan adalah $94 \%$ responden yang menjawab setuju. Hal tersebut menyimpulkan bahwa persepsi mahasiswa jurusan akuntansi Politeknik Pos Indonesia yang belum menempuh mata kuliah auditing terhadap profesi akuntan publik termasuk tinggi. Sehingga dapat disimpulkan bahwa persepsi mahasiswa jurusan akuntansi sebelum menempuh mata kuliah auditing telah baik.

\section{Tanggapan Responden Variabel X2 Terhadap Variabel Y}


Pada penelitian ini persepsi mahasiswa diukur menggunakan 9 indikator dan dioperasionalisasikan menjadi 35 pernyataan. Berikut ini adalah pembahasan mengenai indikatorindikator tanggapan responden mengenai persepsi mahasiswa Politeknik Pos Indonesia sesudah menempuh mata kuliah auditing terhadap profesi akuntan publik. Diantaranya sebagai berikut:

1. Indikator 1 (motivasi kualitas) terdiri dari 5 pernyataan.

2. Indikator 2 (motivasi karir) terdiri dari 5 pernyataan.

3. Indikator 3 (minat mengikuti PPAk) terdiri dari 5 pernyataan.

4. Indikator 4 (pengetahuan tentang akuntan publik) terdiri dari 3 pernyataan.

5. Indikator 5 (hak akuntan publik) terdiri dari 3 pernyataan

6. Indikator 6 (kewajiban akuntan publik) terdiri dari 3 pernyataan

7. Indikator 7 (tanggung jawab profesi) terdiri 3 pernyataan

8. Indikator 8 (perilaku profesional) terdiri dari 3 pernyataan

9. Indikator 9 (pilihan karir sebagai akuntan publik) terdiri dari 5 pernyataan

Tabel 3.7 Tanggapan Responden Variabel X2 terhadap Variabel Y

\begin{tabular}{|l|r|r|r|r|r|}
\hline \multirow{2}{*}{\multicolumn{1}{|c|}{ Indikator }} & \multicolumn{5}{c|}{ Tanggapan Responden } \\
\cline { 2 - 6 } & \multicolumn{1}{|c|}{ SS } & \multicolumn{1}{|c|}{ S } & \multicolumn{1}{c|}{ R } & \multicolumn{1}{c|}{ TS } & STS \\
\hline Motivasi Kualitas & $43 \%$ & $54,4 \%$ & $2,2 \%$ & $0,40 \%$ & $0 \%$ \\
\hline Motivasi Karir & $35,8 \%$ & $54,8 \%$ & $8 \%$ & $1,2 \%$ & $0 \%$ \\
\hline Minat mengikuti PPAk & $35,0 \%$ & $51,2 \%$ & $13,0 \%$ & $0,8 \%$ & $0 \%$ \\
\hline Pengetahuan tentang AP & $32,6 \%$ & $52 \%$ & $12 \%$ & $3,4 \%$ & $0 \%$ \\
\hline Hak Akuntan Publik & $49,6 \%$ & $48,6 \%$ & $1,8 \%$ & $0 \%$ & $0 \%$ \\
\hline Kewajiban Akuntan Publik & $53 \%$ & $43,6 \%$ & $1,8 \%$ & $0 \%$ & $0 \%$ \\
\hline Tanggung Jawab Profesi AP & $65,7 \%$ & $33,0 \%$ & $1 \%$ & $0,3 \%$ & $0 \%$ \\
\hline Perilaku Profesional & $46,0 \%$ & $39,6 \%$ & $10,4 \%$ & $4 \%$ & $0 \%$ \\
\hline Pilihan Karir sebagai AP & $38,8 \%$ & $48,8 \%$ & $11 \%$ & $1 \%$ & $0 \%$ \\
\hline Akumulasi Jawaban Responden & $\mathbf{4 4}$ & $\mathbf{4 8}$ & $\mathbf{7}$ & $\mathbf{1}$ & $\mathbf{0}$ \\
\hline
\end{tabular}

(Sumber : Data primer diolah)

Dari tabel diatas dapat dilihat bahwa sebesar $44 \%$ responden menjawab sangat setuju, $48 \%$ responden menjawab setuju, $7 \%$ responden menjawab ragu-ragu, $1 \%$ responden menjawab tidak setuju dan $0 \%$ responden menjawab sangat tidak setuju. Jika diakumulasikan adalah $92 \%$ responden yang menjawab setuju. Hal tersebut menyimpulkan bahwa persepsi mahasiswa jurusan akuntansi Politeknik Pos Indonesia yang sudah menempuh mata kuliah auditing termasuk tinggi.Sehingga dapat disimpulkan bahwa persepsi mahasiswa jurusan akuntansi Politeknik Pos Indonesia sesudah menempuh mata kuliah auditing terhadap profesi akuntan publik telah baik.

Berdasarkan perhitungan program SPSS for windows version 20.00 (Statistic Program for Social Science, dengan menggunakan pengujian man whitney, maka dapat diambil kesimpulan bahwa tidak terdapat perbedaan yang signifikan antara persepsi mahasiswa jurusan akuntansi Politeknik Pos Indonesia sebelum dan sesudah menempuh mata kuliah auditing terhadap profesi akuntan publik. Ini membuktikan bahwa persepsi mahasiswa jurusan akuntansi Politeknik Pos Indonesia sebelum dan sesudah menempuh mata kuliah auditing terhadap profesi akuntan publik telah terbentuk dengan baik.

Hasil penelitian ini pun sejalan dengan yang dijelaskan Wiliam Andersen Anis Chariril "Tidak ditemukan perbedaan persepsi antara reponden mahasiswa dan mahasiswi mengenai profesi akuntan, 
baik akuntan publik, akuntan pendidik, akuntan perusahaan dan akuntan pemerintah". Begitupun dengan hasil penelitian ini tidak terdapat perbedaan persepsi mahasiswa jurusan akuntansi Politeknik Pos Indonesia sebelum dan sesudah menempuh mata kuliah auditing terhadap profesi akuntan publik.

\section{SIMPULAN DAN SARAN}

\section{Simpulan}

1. Persepsi mahasiswa jurusan akuntansi Politeknik Pos Indonesia sebelum menempuh mata kuliah auditing terhadap profesi akuntan publik telah berjalan dengan baik.

2. Persepsi mahasiswa jurusan akuntansi Politeknik Pos Indonesia sesudah menempuh mata kuliah auditing terhadap profesi akuntan publik telah berjalan dengan baik.

3. Tidak terdapat perbedaan yang signifikan antara persepsi mahasiswa jurusan akuntansi Politeknik Pos Indonesia sebelum dan sesudah menempuh mata kuliah auditing terhadap profesi akuntan publik.

\section{Saran}

Bagi peneliti selanjutnya, perlu menambahkan sampel penelitian, karena semakin banyak sampel, semakin besar kesempatan untuk memberikan gambaran hasil penelitian yang maksimal.

\section{REFERENSI}

[1] Ikatan Akuntan Indonesia.2011. Standar Profesional Akuntan Publik. Jakarta : Salemba Empat

[2] Sodikin, Slamet Sugiri \& Bogat Agus Riyono.2014 Akuntansi Pengantar 1. Jakarta : UPP STIM YKPN

[3] Sugiyono. 2015. Metode Penelitian Kuantitatif Kualitatif dan $R \&$ D. Bandung: Alfabeta.

[4] Undang-Undang Republik Indonesia Nomor 5 Tahun 2011 Tentang Akuntan Publik. 2011.

[5] Wiliam Andersen Anis Chariril.2012.Analisis Persepsi Mahasiswa Akuntansi Dalam Memilih Profesi Sebagai Akuntan. Universitas Diponogoro Semarang. 